\title{
CARACTERÍSTICAS PESSOAIS DOS EMPREENDEDORES: CLARIFICAÇÃO CONCEITUAL DOS CONSTRUTOS E DEFINIÇÕES DA LITERATURA RECENTE (2010-2015)
}

Pedro Afonso Cortez

Universidade São Francisco

\author{
Heila Magali da Silva Veiga
}

Universidade Federal de Uberlândia

\begin{abstract}
Resumo
O estudo das características pessoais dos empreendedores possui longa data e ampla influência interdisciplinar. Pela diversidade de contribuições, identifica-se na literatura confusão e sobreposição conceitual. Nesse sentido, o objetivo geral do estudo foi clarificar os conceitos relativos às características pessoais dos empreendedores presentes na literatura recente. Para tanto, analisaram-se seis construtos com recorrência na literatura em língua portuguesa e inglesa empregados em artigos resgatados por meio do Portal de Periódicos da CAPES publicados entre os anos de 2010 e 2015. Os resultados confirmaram as dificuldades teórico-conceituais existentes na literatura, especificamente em relação aos construtos competências empreendedoras, perfil empreendedor, personalidade empreendedora, potencial empreendedor e performance empreendedora, sendo claramente distinguível dos demais apenas o conceito de atitude empreendedora. Com isso, sugerem-se estudos futuros abrangendo outros conceitos sobre o fenômeno, a fim de aprimorar a estruturação do corpo de conhecimento sobre as características pessoais dos empreendedores.
\end{abstract}

Palavras-chave: empreendedorismo; atitudes; traços de personalidade; perfil empreendedor; revisão de literatura.

\section{PERSONAL CHARACTERISTICS OF ENTREPRENEURS: CLARIFYING CONCEPTS OF RECENT LITERATURE (2010-2015)}

\begin{abstract}
The study of entrepreneurs' personal characteristics has interdisciplinary influence. The diversity of contributions associates with literature's confusion and conceptual overlap. In this sense, the goal of the study was clarifying the concepts related to entrepreneurs' personal characteristics present in recent literature. Therefore, we analyzed six concepts used more than once in Portuguese and English articles retrieved through CAPES portal considering the publication period from 2010 to 2015 . The results confirmed the theoretical and conceptual difficulties in the literature, specifically related to the constructs of entrepreneurial competencies, entrepreneur profile, entrepreneurial personality, entrepreneurial potential and entrepreneurial performance. Only the concept of entrepreneurial attitude is clearly distinguishable from the others. Thus, we suggest future studies involving other concepts about the phenomenon to improve the structure of knowledge about entrepreneurs' personal characteristics.
\end{abstract}

Keywords: entrepreneurship; attitudes; personality traits; entrepreneurial profile; literature review. 


\title{
LAS CARACTERÍSTICAS PERSONALES DE LOS EMPRENDEDORES: ACLARANDO CONCEPTOS DE LA LITERATURA RECIENTE (2010-2015)
}

\begin{abstract}
Resumen
El estudio de las características personales de los emprendedores tiene influencia interdisciplinaria. La diversidad de las contribuciones se asocia con la confusión de la literatura y la superposición conceptual. En este sentido, el objetivo de este estudio fue aclarar los conceptos relacionados con las características personales de emprendedores en la literatura reciente. Por lo tanto, se analizaron seis conceptos utilizados más de una vez en los artículos en portugués e inglés recuperados a través del portal CAPES considerando el período de publicación desde 2010 a 2015 . Los resultados confirmaron las dificultades teóricas y conceptuales en la literatura, específicamente relacionados con los conceptos de las competencias del emprendedor, perfil del emprendedor, personalidad del emprendedor, potencial del emprendedor y rendimiento del emprendedor. Solamente el concepto de actitud del emprendedor se distingue claramente de los otros. En este caso, se sugiere futuros estudios que incluyan otros conceptos sobre el fenómeno con el fin de mejorar la estructura de conocimiento acerca de las características personales del emprendedor.

Palabras clave: espíritu empresarial; actitudes; rasgos de personalidad; perfil emprendedor; revisión de literatura.
\end{abstract}

\section{INTRODUÇÃO}

A palavra empreender é originária do latim medieval (imprehendere) e surgiu por volta do século XV significando a realização de empreendimento laborioso e difícil (Vale, 2014). Partindo da perspectiva histórica do fenômeno, verifica-se que as primeiras referências ao termo empreendedor ocorreram na França tendo seu uso datado no ano 1709. Entretanto, o uso do termo empreendedor somente foi empregado para se referir a alguém que controla uma empresa por volta de 1770 mediante a proposição do termo por Abbé Galiani. A popularização do vocábulo aconteceu a posteriori nos escritos de Saint Simon por volta de 1823 (Braudel, 1982).

A utilização do termo empreendedor como aquele que controla uma empresa coincide com o contexto de época em que emergiam na França empresas com características capitalistas (Braudel, 1982). No decorrer do século XIX, o conceito se ampliou e alterou o significado, associando-se aos domínios de política, guerra, dinheiro e justiça, designando sujeitos com relativa influência na realidade social (Vérin, 1982). Foi também no início do século XIX, com o desenvolvimento de trabalhos pelos economistas ingleses, que 0 termo empreendedor se associou à ideia de provedor de capital financeiro, prosperado principalmente pela influência do exorbitante crescimento industrial (Hébert \& Link, 2010).

É também no século XIX que o termo empreendedor foi incorporado formalmente à literatura, principalmente inglesa, referindo-se ao empreendedor como aquele empresário que acumulava capitais (Hoselitz, 1952). De forma mais atual, identifica-se nas elaborações de Schumpeter $(1939,1985)$ o resgate do termo para designar o empreendedor como agente ativo no ciclo de desenvolvimento de capitais por meio da destruição criativa e promoção da 
inovação. Em seu contexto de época, Schumpeter (1985) insere o empreendedor como central no desenvolvimento das economias capitalistas, sendo o sujeito responsável pelo progresso econômico.

Outras contribuições para compreender o empreendedor referem-se aos escritos sociológicos de Weber (1958) que identificaram na ética protestante práticas sociais que influenciaram comportamentos voltados ao empreendedorismo, tais como: trabalhar para dignificar-se frente ao sagrado e acumular capitais reinvestindo os frutos do trabalho no próprio negócio para adequar-se à doutrina calvinista. Ainda na sociologia, teóricos associaram o empreendedor ao sujeito excluído socialmente, apto a assumir riscos e a se comportar de forma desviante, estabelecendo iniciativas destoantes do padrão vigente (Hoselitz, 1957; Dana, 2007).

Já na segunda metade do século $X X$, evidenciou-se 0 início da compreensão do fenômeno por meio de ciências voltadas para a análise das características individuais. Na psicologia, as primeiras compreensões sobre o termo empreendedor surgem por meio dos estudos de McClelland (1965) os quais analisaram os fatores psicológicos que influenciam um indivíduo ao empreendedorismo. Em seus estudos, McClelland (1972) partiu das motivações e características pessoais para compreender o que distingue o empreendedor dos demais indivíduos, o que o permitiu verificar que, no que tange às características pessoais, os empreendedores apresentam maior necessidade de realização que a população geral.

Da proposição das características pessoais relativas aos empreendedores por McClelland (1972) até o presente momento, inúmeros estudos se desenvolveram mantendo o campo de conhecimento sobre as características pessoais dos empreendedores repleto de conceitos, formulações e reformulações a respeito do fenômeno. Por essa diversidade conceitual, observam-se ainda hoje embates teóricos relevantes e questões conceituais relativas ao empreendedorismo não resolvidas, principalmente no que tange às características pessoais que definem os aspectos psicológicos do sujeito empreendedor (Hisrich, Langan-Fox, \& Grant, 2007; Frese \& Gielnik, 2014).

Para Hisrich et al. (2007), a multiplicidade conceitual existente em análises sobre o fenômeno enriquece o espectro de compreensão sobre o empreendedor, mas dificulta a proposição de agendas concretas de pesquisa e prática, tendo em vista a impossibilidade de comparar as elaborações no campo do empreendedorismo por conta da elevada dispersão teórica. Numa meta-análise sobre as características pessoais dos empreendedores, Frese e Gielnik (2014) identificaram sobreposição entre os construtos que versam sobre o tema, o que deve ser esclarecido por estudos de revisão que busquem clarificar e distinguir conceitos voltados para a apreensão do fenômeno. Partindo dessa proposição, o objetivo geral da presente investigação foi identificar os construtos relacionados com as características pessoais dos empreendedores na literatura recente, bem 
como descrever os principais elementos teórico-conceituais dos construtos analisados.

\section{MÉTODO}

Para possibilitar a identificação dos construtos para análise, o primeiro passo foi definir os descritores para recuperação dos estudos. Dado que o principal foco de interesse do presente trabalho são as características pessoais referentes ao empreendedor, optou-se por elencar as seguintes palavras-chave, as quais tiveram maior ocorrência durante a análise exploratória da literatura: perfil empreendedor (entrepreneur profile; entrepreneurial profile); atitude empreendedora (entrepreneurial attitude; entrepreneur atitude); características empreendedoras (entrepreneurial characteristics; entrepreneur characteristics). Elegeu-se como critério de inclusão artigos científicos indexados no Portal de Periódicos da Comissão de Aperfeiçoamento de Pessoal do Nível Superior (CAPES) em língua portuguesa e inglesa. Nas buscas preliminares localizaram-se 209 artigos no total. Com a leitura exploratória desses artigos, verificaram-se que 122 apresentavam pertinência ao objeto da presente revisão no título e resumo, os quais foram resgatados na íntegra.

Contudo, após a leitura integral dos estudos apurou-se que grande parte dos trabalhos utilizava conceitos citados uma única vez e sem recorrência em estudos recentes, o que tornava a clarificação conceitual inexequível pelo elevado número de estudos propondo construtos com ocorrência única na literatura. Assim, com o intuito de limitar a quantidade de construtos, optou-se por restringir o recorte temporal para o período entre 2010 e 2015. Para o quinquênio descrito, obteve-se o total de 29 artigos, nos quais foram identificados 17 construtos versando sobre as características pessoais dos empreendedores. A codificação empregada para analisar a ocorrência dos construtos nos estudos foi realizada de forma independente por dois pesquisadores da área, a fim de apurar a confiabilidade do procedimento empregado. Na Tabela 1 são apresentados os construtos identificados e a frequência de codificação do termo para cada um dos levantamentos $\left(L_{1}\right.$ e $\left.L_{2}\right)$ a partir dos 29 estudos identificados no quinquênio.

Tabela 1. Percentual de concordância entre avaliadores na codificação dos construtos

\begin{tabular}{lccc}
\hline \multicolumn{1}{c}{ Construto } & $\mathrm{L}_{1}$ & $\mathrm{~L}_{2}$ & $\begin{array}{c}\% \text { de } \\
\text { concordância }\end{array}$ \\
\hline Competências Empreendedoras & 4 & 4 & $100 \%$ \\
Empreendedor (termo genérico) & 4 & 3 & $75 \%$ \\
Perfil Empreendedor & 3 & 3 & $100 \%$ \\
Potencial Empreendedor & 3 & 3 & $100 \%$ \\
\hline
\end{tabular}




\begin{tabular}{lccc}
\hline Personalidade Empreendedora & 3 & 3 & $100 \%$ \\
Atitude Empreendedora & 3 & 3 & $100 \%$ \\
Performance Empreendedora & 2 & 2 & $100 \%$ \\
Propensão Empreendedora & 1 & 1 & $100 \%$ \\
Inclinação Empreendedora & 1 & 1 & $100 \%$ \\
Postura Empreendedora & 1 & 1 & $100 \%$ \\
Intraempreendedorismo & 1 & 1 & $100 \%$ \\
Intenção Empreendedora & 1 & 1 & $100 \%$ \\
Habilidade Empreendedora & 1 & 1 & $100 \%$ \\
Empreendedor por Necessidade ou & 1 & 1 & $100 \%$ \\
Oportunidade & 1 & 1 & $100 \%$ \\
Empreendedor Imigrante & 1 & 1 & $100 \%$ \\
Coordenador Empreendedor & 1 & 1 & $100 \%$ \\
Características Empreendedoras & na codificação entre & $98,5 \%$ \\
\hline Percentual total médio de concordância \\
avaliadores
\end{tabular}

Nota. $\mathrm{L}_{1}=$ frequência de ocorrência do construto codificada pelo primeiro avaliador; $L_{2}=$ frequência de ocorrência do construto codificada pelo segundo avaliador

Inspecionando-se a Tabela 1 , observa-se que houve elevado índice de concordância entre as codificações independentes $(98,5 \%)$, o que aponta robustez quanto à replicabilidade dos critérios de codificação estabelecidos (Polit \& Beck, 2006). Nos dois levantamentos houve total concordância entre os avaliadores em relação aos dez construtos com ocorrência única na literatura, os quais mantiveram-se excluídos do processo de clarificação conceitual. Ressaltase que a única discordância entre os dois avaliadores se refere ao termo empreendedor utilizado de forma genérica como possuidor do próprio negócio sem qualquer conceitualização teórica para o conceito.

Assim, optou-se por também excluir da clarificação conceitual esse conceito, apesar da recorrência na literatura, devido à discordância entre os juízes e a compreensão de que a ausência de descrição do quadro teórico para o termo o descaracterizava da concepção de construto. Destaca-se que, após a codificação, optou-se por realizar a análise teórico-conceitual dos construtos com recorrência na literatura, tendo em vista que a restrição do recorte temporal não foi suficiente para diminuir a quantidade de construtos com ocorrência única. Cabe enfatizar que a estratégia de realizar a análise a partir de conceitos recorrentes é comum ao tratar de construtos multifacetados com elevada dispersão teórico-conceitual (Trotter, 2012). Dessa forma, fez-se essa opção por considerar irrelevante a clarificação de construtos com ocorrência única na literatura, tendo em vista a saturação teórica do fenômeno em análise (O'Reilly \& Parker, 2013; Fontanella et al., 2011). 
Especificamente, a clarificação conceitual versou sobre seis construtos identificados em 16 artigos com recorrência na codificação e plena concordância entre os avaliadores $\left(L_{1}\right.$ e $\left.L_{2}\right)$. Os critérios empregados para resgatar os textos e identificar a ocorrência dos construtos na literatura são sintetizados por meio da Figura 1.

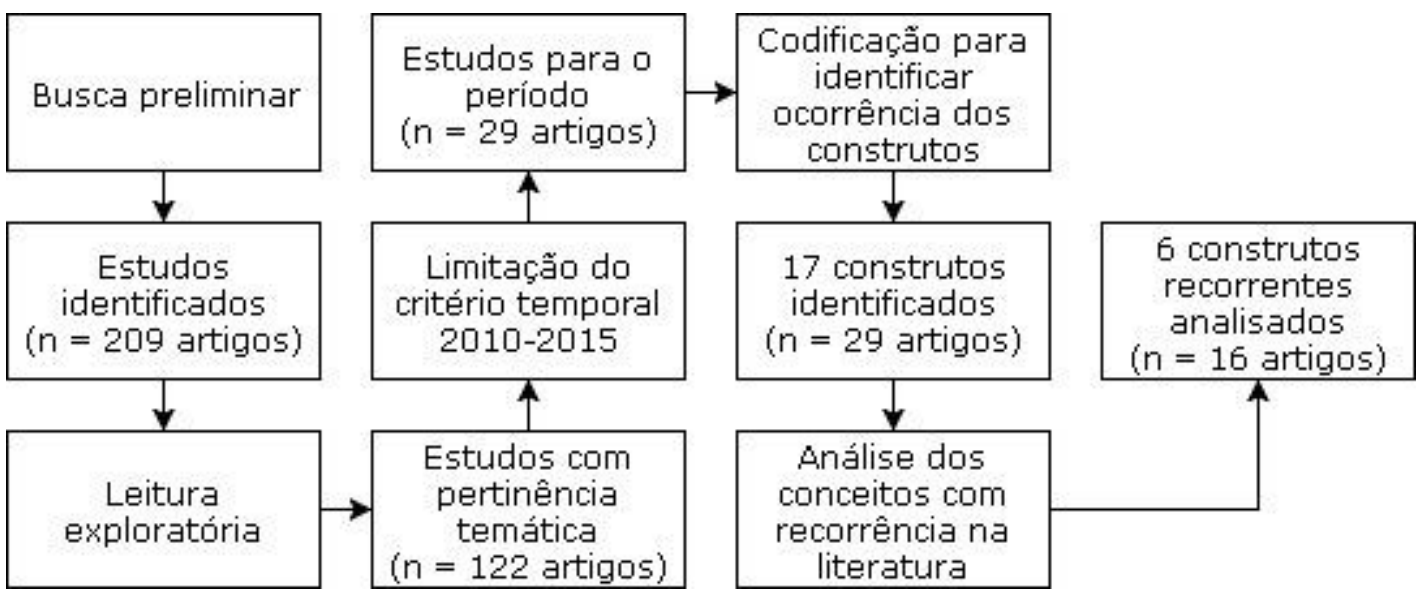

Figura 1. Procedimentos empregados na identificação e categorização dos construtos

\section{RESULTADOS}

Considerando-se a concordância encontrada nos levantamentos $L_{1}$ e $L_{2}$, realizou-se a análise teórico-conceitual dos seguintes construtos: 1) competências empreendedoras; 2) atitude empreendedora; 3) personalidade empreendedora; 4) potencial empreendedor; 5) perfil empreendedor e 6) performance empreendedora. Com o intuito de facilitar a compreensão dos aspectos essenciais desses construtos, optou-se por apresentar a clarificação conceitual de cada um deles individualmente nas subseções a seguir.

\section{Competências Empreendedoras}

Para Zampier e Takahashi (2011) as competências empreendedoras são definidas como um corpo de conhecimento, área, habilidade, qualidades pessoais, características, atitudes, visões, motivações e direcionamentos que podem contribuir para o pensamento ou ação efetiva do negócio e que permite ao indivíduo imprimir ações, estratégias e visão na criação de valor tangível e intangível para a sociedade. Na definição de Rezaei-Zadeh, Hogan, O’Reilly, Cleary e Murphy (2014), as competências empreendedoras representam certas características ou capacidades da pessoa que permitem a execução de ações empreendedoras, incluindo a identificação de oportunidades e criação ou manutenção do próprio negócio.

$\mathrm{Na}$ acepção das competências empreendedoras, Santandreu-Mascarell, Garzon e Knorr (2013) utilizaram a proposta de Garzón (2010) que concebe as 
competências empreendedoras como um construto multidimensional composto por realização (oportunidade e iniciativa, assunção ao risco, demanda por eficiência e qualidade, persistência e comprometimento com o contrato de trabalho), planejamento (busca por informações, orientação à meta, planejamento sistemático e monitoramento) e poder (persuasão e rede de contatos, independência e auto eficácia). Por sua vez, Obschonka, Silbereisen e Schmitt-Rodermund (2012) não trazem uma definição para o construto e apenas citam fatores relacionados como liderança, invenção e execução de atividade comercial. Dessa forma, nota-se que os modelos de competências empreendedoras adotados pelos estudos divergem entre si, apesar de alguns utilizarem das elaborações de McClelland (1965) como fundamental para a proposição do construto.

Destaca-se que nos estudos de Zampier e Takahashi (2011) e SantandreuMascarell et al. (2013) a origem das competências empreendedoras situa-se na tipologia de traços de McClelland abrangendo dimensões sobre oportunidade e iniciativa, assunção ao risco, eficiência e qualidade, persistência, comprometimento com o trabalho, busca por informação, orientação à meta, planejamento e monitoramento sistemático do trabalho, rede de contatos e auto eficácia (Cooley, 1990; Garzón, 2010). Acrescenta-se ainda, em relação ao estudo de Zampier e Takahashi (2011), a elaboração de seis dimensões de segunda ordem para as competências empreendedoras com base no modelo de Man e Lau (2000), que são: oportunidade, relacionamentos, conceituais, administrativas, estratégicas e comprometimento, as quais enfatizam as características pessoais do indivíduo voltadas para a realização da atividade empreendedora.

Mantendo-se a análise das competências empreendedoras, observa-se origem diferente para o construto na investigação de Rezaei-Zadeh et al. (2014), pois o uso do termo competência é atribuído a Boyatzis (1982) dirigindo maior ênfase para 0 aspecto comportamental atrelado aos resultados do empreendedor. Na definição de Rezaei-Zadeh et al. (2014), as competências empreendedoras compreendem um conjunto de características que permitem a demonstração de comportamentos estritamente relacionados ao sucesso e a manutenção do empreendimento. Por fim, a pesquisa realizada por Obschonka et al. (2012) não apresenta definição constitutiva para o construto competências empreendedoras e emprega uma medida estritamente comportamental buscando avaliar experiências prévias na adolescência que propiciem o desenvolvimento de competências ao empreendedor (Schröder \& Schmitt-Rodermund, 2006).

Logo, é possível verificar que os estudos sobre competências empreendedoras oscilam entre compreender o construto por meio das elaborações de McClelland (1965) e Boyatzis (1982). Nos modelos pautados na concepção de McClelland (1965), as competências empreendedoras são relacionadas a comportamentos e habilidades necessários para a execução da 
atividade empreendedora. Nas propostas fundamentadas na concepção de competências de Boyatzis (1982), a acepção do construto supera a proposição metafórica de características pessoais baseadas em McClelland (1965) e visam, além de aspectos que habilitam a expressão do empreendedorismo, compreender elementos pessoais que agreguem resultado à atividade empreendedora.

\section{Atitude Empreendedora}

Tratando-se da atitude empreendedora, Choe, Loo e Lau (2013) a concebem como um construto multidimensional baseado no modelo tripartite de atitudes (cognição, afeto e volição comportamental), o qual é operacionalizado por meio de cinco fatores (realização, autoestima, autocontrole, inovação e reconhecimento de oportunidades). A definição de Arribas, Hernandez, Urbano e Vila (2012) para o construto refere-se ao posicionamento positivo do indivíduo frente à intenção de empreender e opção de criar um negócio em detrimento a ser empregado por outra pessoa. Por sua vez, Lope-Pihie e Bagheri (2011) também partem do modelo tripartite de atitudes para designar a atitude empreendedora, definindo-a como a percepção de valência positiva frente à aspectos pessoais relacionados com o empreendedorismo, integrando valores e benefícios obtiveis pelo indivíduo ao empreender. Ainda na visão de Lope-Pihie e Bagheri (2011) trata-se de um construto multidimensional representado pelos fatores realização, autoestima, autocontrole e inovação. No caso dos estudos de Choe et al. (2013) e Lope-Pihie e Bagheri (2011) o modelo empregado para conceber a atitude empreendedora tem inspiração no estudo de Robinson, Stimpson, Huefner e Hunt (1991), os quais compartilham entre si acepção de atitudes a partir do modelo tripartite (Lindzey, Gilbert, \& Fiske, 1998).

Entretanto, apesar da similaridade entre os autores no que tange ao modelo tripartite para conceber a atitude empreendedora, nota-se relativa diferença entre os fatores elencados pelos estudos para o construto, uma vez que Choe et al. (2013) incluem o fator reconhecimento de oportunidades, a partir de evidência sugerida pela literatura (McCline, Bhat, \& Baj, 2000), ao passo em que Lope-Pihie e Bagheri (2013) mantêm a operacionalização original proposta por Robinson et al. (1991). Em relação à pesquisa realizada por Arribas et al. (2012) não existe um modelo teórico que sustente a proposição de atitude dos autores, o que torna limitada a contribuição deste estudo para a compreensão do conceito de atitude empreendedora, uma vez que sem definição constitutiva e proposição de modelo teórico, não é possível afirmar com precisão qual modelo teórico o autor se baseia. Por essa razão, nota-se que o modelo teórico predominante para o construto atitude empreendedora, refere-se à concepção tripartite de atitudes, sendo identificável na contribuição de Robinson et al. (1991) uma acepção para o construto replicada na literatura. 


\section{Personalidade Empreendedora}

Identifica-se nos estudos analisados equivalência entre o modelo Big Five de personalidade e o construto personalidade empreendedora. O modelo Big Five é baseado numa descrição psicolexical de facetas gerais da personalidade por meio dos fatores conscienciosidade, abertura à experiência, extroversão, afabilidade e neuroticismo (John \& Srivastava, 1999). Por sua vez, o construto personalidade empreendedora proposto por Obschonka, Schmitt-Rodermund, Silbereisen, Gosling e Potter (2013) é definido como um conjunto de traços do modelo Big Five em termos de níveis mais elevados de extroversão, conscienciosidade e abertura à experiência, conjuntamente a graus mais baixos em afabilidade e neuroticismo (Obschonka et al., 2013). De forma semelhante, Mathieu e St-Jean (2013) também utilizam do modelo Big Five para caracterizar a personalidade empreendedora descrevendo-a apenas em termos de elevados escores de extroversão e abertura à experiência, conjuntamente a baixos graus de neuroticismo e afabilidade.

Essa proposição de personalidade empreendedora também aparece na investigação de Obschonka et al. (2012), os quais definem o construto como o maior escore possível em extroversão, conscienciosidade e abertura à experiência, associado ao menor índice de afabilidade e neuroticismo (SchmittRodermund, 2004, 2007). Sendo assim, ao tratar sobre a definição de personalidade empreendedora a literatura não designa um construto independente, refere-se à associação de níveis específicos de fatores encontrados no modelo Big Five, o que permite questionar se a terminologia utilizada é adequada ou se não impacta em maior confusão conceitual na área, sugerindo de forma equivocada a existência de um construto independente chamado personalidade empreendedora, ao passo em que se trata do Big Five (John \& Srivastava, 1999).

\section{Potencial Empreendedor}

Voltando-se para a análise do construto potencial empreendedor, encontra-se no estudo de Iizuka e Moraes (2014) uma acepção para o construto a partir de experiências que predispõem o indivíduo para a criação do próprio negócio. Entre as experiências relacionadas por Iizuka e Moraes (2014) para o surgimento do potencial empreendedor estão: o apoio materno (Murray \& Cabral, 1978), parentes de primeiro grau com negócio próprio (Matthews \& Moser, 1996; Scherer, Adams, \& Wiebe, 1989) e atividades anteriores ao período universitário descritas pelos autores como "quanto maior e mais diversificado o conjunto de atividades realizadas, relacionadas ao desenvolvimento do próprio empreendimento, maior o potencial empreendedor do estudante" (Iizuka \& Moraes, 2014, p. 606). Outros autores adotam para a definição do construto a ideia de que o potencial empreendedor define as pessoas que não começaram 
seus negócios ainda, mas conseguem se imaginar fazendo isso em um futuro próximo, ou seja, nos próximos três anos (Morales \& Marquina, 2013).

De maneira divergente às propostas de Iizuka e Moraes (2014) e Morales e Marquina (2013) que associam o potencial empreendedor, respectivamente, às experiências pessoais ou à vontade de criar o próprio negócio num futuro próximo, Santos, Caetano, Curral e Spagnoli (2010) propõem o potencial empreendedor como um construto composto pelos fatores desejo de independência, motivação econômica, capacidade de inovação, inteligência emocional, resiliência, capacidade de comunicação e persuasão, capacidade para desenvolver redes sociais, auto eficácia empreendedora, visão, capacidade para mobilizar recursos e capacidade para liderar. Esse modelo de potencial empreendedor proposto por Santos et al. (2010) pode ainda ser agrupado em quatro dimensões de segunda ordem, que são: as motivações empreendedoras, as competências psicológicas, as competências sociais e as competências de gestão.

Nesse sentido, verifica-se que não há consenso entre os autores quanto à definição do potencial empreendedor, nem sobre os fatores que o compõem, ora designando experiências pessoais que facilitam a expressão do empreendedorismo, ora versando sobre características pessoais relacionadas à manifestação do ato de empreender. Entre os estudos analisados, nota-se que a proposta de Santos et al. (2010) confunde-se, em grande parte, com o construto de competências empreendedoras, não contribuindo para diferenciar o construto potencial empreendedor dos demais. As elaborações de Iizuka e Moraes (2014) e Morales e Marquina (2013), apesar de distintas entre si, resguardam um ponto de diferenciação para o construto ao designar o potencial empreendedor como um estado latente, anterior à expressão do empreendedorismo pelo sujeito. Enfatizando-se o aspecto latente ressaltado pelos autores, parece viável propor uma definição para o potencial empreendedor que o distingue dos demais construtos analisados. Nesse sentido, o potencial empreendedor se diferenciaria dos demais construtos ao ser compreendido como um estado de predisposição individual para criar o próprio negócio num futuro próximo, o qual pode ser impactado por experiências que favoreçam a transformação da potência em ato manifesto, ou seja, a execução da atividade empreendedora.

\section{Perfil Empreendedor}

Em relação ao perfil empreendedor, Souza e Silva (2011) utilizam das dimensões propostas por Schmidt e Bohnenberger (2009) para defini-lo: autoeficaz, assume riscos calculados, planejador, detecta oportunidades, persistente, sociável, inovador e líder. Iizuka e Moraes (2014) também fazem uso dos fatores propostos por Schmidt e Bohnenberger (2009) na operacionalização do perfil empreendedor. Para a proposição das dimensões referentes ao perfil empreendedor Schmidt e Bohnenberger (2009) se 
fundamentaram numa miscelânea de literatura sobre o tema, a fim de operacionalizar o construto em fatores. Por sua vez, Brants, Oliveira, Casemiro, Licório e Reboli (2015) se inspiraram nas características de McClelland (1965) para propor sua própria definição adaptada de perfil empreendedor, a qual abrange as seguintes dimensões: busca de oportunidade e iniciativa, persistência, comprometimento, exigência de qualidade e eficiência, correr riscos calculados, estabelecimento de metas, busca de informações, planejamento e monitoramento sistemático, persuasão e rede de contatos, independência e autoconfiança.

De maneira geral, as propostas de Souza e Silva (2011) e Iizuka e Moraes (2014) replicam as elaborações de Schmidt e Bohnenberger (2009) sem buscar novas evidências de validade para o construto, nem aprimorar os aspectos teóricos da noção de perfil empreendedor, o que implica na manutenção das dificuldades conceituais e empíricas relativas ao construto. Cabe ainda destacar que os fatores elencados por Schmidt e Bohnenberger (2009) surgem por meio de levantamento assistemático de estudos relacionados ao empreendedorismo, os quais foram agrupados e nomeados pelos autores sem considerações acerca do aporte teórico que fundamenta o modelo dos autores de perfil empreendedor. Proposição semelhante de dimensões desconectadas das evidências recentes da literatura também aparece na proposta de Brants et al. (2015) para o construto. No caso do estudo de Souza e Silva (2011) parece haver confusão entre a definição de perfil empreendedor e a operacionalização do construto, pois os autores nomeiam os fatores referentes ao perfil como características atitudinais, mas operacionalizam o modelo por meio da noção de traços. Essa ambiguidade torna possível questionar se construto se baseia em um aporte teórico atitudinal ou refere-se à concepção de traços estáveis, tendo em vista o emprego do termo perfil.

Além disso, nos estudos de Souza e Silva (2011) e de Iizuka e Moraes (2014) o referencial teórico abarcado para o desenvolvimento do conceito de perfil empreendedor utiliza de forma recorrente as contribuições de McClelland (1972), tal como realizado pela literatura referente à atitude empreendedora (Robinson et al., 1991), além de uma miscelânea de outros estudos que não apresentam robustez para sustentar de forma empírica os fatores que os autores pretendem definir. Dessa forma, é possível questionar a relevância do construto perfil empreendedor, pois, ao se considerar a confusão conceitual entre os termos atitude e perfil replicada pelos autores (Souza \& Silva, 2011) e a semelhança na literatura utilizada para fundamentar o construto perfil empreendedor (Schmidt \& Bohnenberger, 2009) com aquela empregada para o construto atitude empreendedora (Robinson et al., 1991), nota-se sobreposição conceitual entre os construtos perfil empreendedor e atitude empreendedora. A sobreposição conceitual ocorre quando dois conceitos nomeados de formas distintas não se diferenciam entre si, seja pelo pressuposto teórico que os 
sustentam, definem ou operacionalizam, o que demanda por investigações que busquem clarificá-los (Bastos, 1994).

Sendo assim, entre os construtos perfil empreendedor $e$ a atitude empreendedora verifica-se que o construto atitudinal apresenta maior consistência teórica, uma vez que dispõe de clareza conceitual quanto à definição e operacionalização a partir da concepção tripartite de atitudes (Lindzey et al., 1998). Aliás, cabe ressaltar que o modelo de traços foi utilizado de forma recorrente na literatura como uma metáfora da proposta inicial dos fatores elencados por McClelland (1965) para descrever o empreendedor, mas não se mostrou profícuo para a compreensão do fenômeno, sendo, a posteriori, substituído pelo modelo atitudinal que facilitou as investigações sobre o tema por se dirigir a domínios mais específicos do empreendedorismo (Robinson et al., 1991). Além disso, o emprego da nomenclatura perfil pode resultar em confusões conceituais, uma vez que se associa a ideia de traço estável, a qual não é possível afirmar em relação à maior parte dos construtos referentes ao empreendedorismo no nível individual, considerando-se as evidências apontadas por meta-análise recente (Frese \& Gielnik, 2014).

\section{Perfomance Empreendedora}

Referindo-se à performance empreendedora verifica-se que a definição adotada pelo estudo de Shane e Nicolaou (2013) restringe a definição do construto à quantidade de dólares obtidos mensalmente pelo empreendedor por meio do próprio negócio. O sentido empregado por Choe et al. (2013) para a performance empreendedora refere-se à auto avaliação do empreendedor quanto ao resultado do próprio negócio frente às demais empresas do mesmo nicho de mercado. Assim, nota-se que a performance empreendedora é um construto que se refere tanto à renda aferida pelo indivíduo, quanto à organização, sendo o termo performance equivalente a desempenho.

Dessa forma, como métrica para avaliar o desempenho das organizações, parece razoável, no nível organizacional, designar o termo performance empreendedora numa concepção estritamente financeira, tal como concebido por Shane e Nicolaou (2013) em estudos que optarem por apreender aspectos econômicos e contábeis das organizações. Contudo, no nível individual, parece inadequado utilizar a métrica estritamente financeira para apurar características pessoais dos empreendedores, uma vez que o resultado financeiro diz respeito primordialmente à organização e sofre interferência de determinantes de outros níveis que impactam nos resultados concretos da empresa, mas não necessariamente apresentam relação com as características pessoais do sujeito empreendedor.

Assim, como métrica de características pessoais, relacionada ao desempenho percebido pelo empreendedor, torna-se razoável utilizar a proposta de Choe et al. (2013), tendo em vista que a métrica obtida por meio autorrelato 
tem maior associação com os aspectos individuais do empreendedor e, portanto, é menos suscetível à influência de variáveis contextuais. De qualquer forma, é importante ressaltar que o construto performance empreendedora deve ser preferencialmente empregado em estudos que buscam compreender a relação entre fenômenos associados ao empreendedorismo em diferentes níveis (micro, meso e macro), a fim de aferir com maior robustez a associação entre o autorrelato do empreendedor sobre o desempenho e o resultado financeiro obtido pela organização no período. Cabe ainda uma ressalva ao termo performance, pois, na literatura voltada para a mensuração de resultados no nível individual, costuma-se empregar o termo desempenho ao tratar dos resultados alcançados pelo sujeito em detrimento da palavra performance (Borges-Andrade \& Coelho-Junior, 2011; Tamayo \& Abbad, 2006). Ademais, com vistas a facilitar a visualização dos resultados relatados até então, apresenta-se na Tabela 2 uma síntese descritiva dos construtos analisados e da clarificação conceitual empreendida.

Tabela 2. Síntese descritiva dos construtos analisados e clarificação conceitual

\begin{tabular}{|c|c|c|c|c|}
\hline Construto & Autores & Definição & Aporte teórico & $\begin{array}{c}\text { Clarificação } \\
\text { conceitual }\end{array}$ \\
\hline \multirow[t]{4}{*}{ I } & $\begin{array}{l}\text { Zampier \& } \\
\text { Takahashi } \\
(2011)\end{array}$ & $\begin{array}{l}\text { Características pessoais } \\
\text { que contribuem para o } \\
\text { pensamento ou ação } \\
\text { efetiva do negócio e que } \\
\text { permite ao indivíduo } \\
\text { agregar valor à } \\
\text { sociedade }\end{array}$ & \multirow{4}{*}{$\begin{array}{l}\text { McClelland (1965): as } \\
\text { competências } \\
\text { empreendedoras são } \\
\text { relacionadas a } \\
\text { comportamentos e } \\
\text { habilidades necessários } \\
\text { para a execução da } \\
\text { atividade } \\
\text { empreendedora } \\
\text { Boyatzis (1982): a } \\
\text { acepção do construto } \\
\text { supera a proposição } \\
\text { metafórica de } \\
\text { características pessoais } \\
\text { baseadas em McClelland } \\
\text { e visam, além de } \\
\text { aspectos que habilitam a } \\
\text { expressão do } \\
\text { empreendedorismo, } \\
\text { compreender elementos } \\
\text { pessoais que agreguem } \\
\text { resultado à atividade } \\
\text { empreendedora }\end{array}$} & \multirow{4}{*}{$\begin{array}{l}\text { Enfatizar os } \\
\text { comportamentos e } \\
\text { habilidades de forma } \\
\text { contextualizada com } \\
\text { ênfase na geração de } \\
\text { resultados, tal como } \\
\text { na acepção de } \\
\text { Boyatzis (1982), a } \\
\text { fim de distingui-los } \\
\text { da atitude } \\
\text { empreendedora }\end{array}$} \\
\hline & $\begin{array}{l}\text { Rezaei- } \\
\text { Zadeh et al. } \\
(2014)\end{array}$ & $\begin{array}{l}\text { Características ou } \\
\text { capacidades da pessoa } \\
\text { que permitem a } \\
\text { execução de ações } \\
\text { empreendedoras }\end{array}$ & & \\
\hline & $\begin{array}{l}\text { Santandreu- } \\
\text { Mascarell et } \\
\text { al. (2013) }\end{array}$ & $\begin{array}{l}\text { Construto } \\
\text { multidimensional } \\
\text { composto pelos fatores } \\
\text { realização, } \\
\text { planejamento e poder }\end{array}$ & & \\
\hline & $\begin{array}{l}\text { Obschonka } \\
\text { et al. (2012) }\end{array}$ & $\begin{array}{l}\text { Sem definição } \\
\text { constitutiva }\end{array}$ & & \\
\hline \multirow[t]{2}{*}{ II } & $\begin{array}{l}\text { Choe et al. } \\
(2013)\end{array}$ & $\begin{array}{l}\text { Construto } \\
\text { multidimensional } \\
\text { composto pelos fatores } \\
\text { realização, autoestima, } \\
\text { autocontrole, inovação e } \\
\text { reconhecimento de } \\
\text { oportunidades }\end{array}$ & $\begin{array}{l}\text { Robinson et al. (1991): } \\
\text { aplicação do modelo } \\
\text { tripartite de atitudes } \\
\text { para avaliar o } \\
\text { posicionamento do } \\
\text { indivíduo em relação às } \\
\text { próprias características }\end{array}$ & \multirow{2}{*}{$\begin{array}{l}\text { Adequação do } \\
\text { modelo tripartite de } \\
\text { atitudes, em oposição } \\
\text { ao modelo de traços, } \\
\text { para compreender as } \\
\text { características } \\
\text { pessoais do } \\
\text { empreendedor pela } \\
\text { possibilidade de } \\
\text { associar aspectos } \\
\text { pessoais a diferentes } \\
\text { contextos relevantes }\end{array}$} \\
\hline & $\begin{array}{l}\text { Arribas et al. } \\
(2012)\end{array}$ & $\begin{array}{l}\text { Posicionamento } \\
\text { individual em relação à } \\
\text { empreender em vez de } \\
\text { trabalhar como } \\
\text { empregado }\end{array}$ & $\begin{array}{l}\text { pessoais associadas ao } \\
\text { contexto de expressão } \\
\text { do empreendedorismo }\end{array}$ & \\
\hline
\end{tabular}


Lope-Pihie \& Valência positiva em

Bagheri relação às próprias

(2011) características pessoais

associadas ao

empreendedorismo

\begin{tabular}{|c|c|c|}
\hline \multirow[t]{3}{*}{ III } & $\begin{array}{l}\text { Obschonka } \\
\text { et al. (2013) }\end{array}$ & $\begin{array}{l}\text { Conjunto de traços do } \\
\text { modelo Big Five em } \\
\text { termos de níveis mais } \\
\text { elevados de } \\
\text { extroversão, } \\
\text { conscienciosidade e } \\
\text { abertura à experiência, } \\
\text { conjuntamente a graus } \\
\text { mais baixos em } \\
\text { afabilidade e } \\
\text { neuroticismo }\end{array}$ \\
\hline & $\begin{array}{l}\text { Mathieu \& } \\
\text { St-Jean } \\
(2013)\end{array}$ & $\begin{array}{l}\text { Elevados escores de } \\
\text { extroversão e abertura à } \\
\text { experiência, } \\
\text { conjuntamente a baixos } \\
\text { graus de neuroticismo e } \\
\text { afabilidade }\end{array}$ \\
\hline & $\begin{array}{l}\text { Obschonka } \\
\text { et al. (2012) }\end{array}$ & $\begin{array}{l}\text { Maior escore possível } \\
\text { em extroversão, } \\
\text { conscienciosidade e } \\
\text { abertura à experiência, } \\
\text { associado ao menor } \\
\text { índice de afabilidade e } \\
\text { neuroticismo }\end{array}$ \\
\hline
\end{tabular}

para o

empreendedorismo

\author{
John e Srivastava \\ (1999): descrição \\ psicolexical de facetas \\ gerais da personalidade \\ por meio modelo Big \\ Five abrangendo os \\ fatores \\ conscienciosidade, \\ abertura à experiência, \\ extroversão, afabilidade \\ e neuroticismo \\ Equivalência entre o \\ construto de \\ personalidade Big \\ Five e a \\ personalidade \\ empreendedora, a \\ utilização de \\ nomenclatura diversa \\ para referir ao \\ mesmo construto \\ impacta em maior \\ confusão conceitual \\ na literatura
}

\begin{tabular}{|c|c|c|c|c|}
\hline IV & $\begin{array}{l}\text { Iizuka \& } \\
\text { Moraes } \\
(2014) \\
\text { Morales \& } \\
\text { Marquina } \\
(2013)\end{array}$ & $\begin{array}{l}\text { Experiências prévias que } \\
\text { facilitam a criação do } \\
\text { próprio negócio } \\
\text { Indivíduos que não } \\
\text { iniciaram o próprio } \\
\text { negócio, mas possuem } \\
\text { predisposição para } \\
\text { iniciá-lo num futuro } \\
\text { próximo } \\
\text { Conjunto de } \\
\text { competências e } \\
\text { motivações relacionadas } \\
\text { à expressão do } \\
\text { empreendedorismo }\end{array}$ & $\begin{array}{l}\text { Modelos concebidos a } \\
\text { partir de ideias } \\
\text { propostas pelos autores, } \\
\text { não dispondo de aporte } \\
\text { anterior para as } \\
\text { elaborações }\end{array}$ & $\begin{array}{l}\text { Possibilidade de } \\
\text { diferenciar o } \\
\text { potencial } \\
\text { empreendedor dos } \\
\text { demais construtos ao } \\
\text { concebê-lo como } \\
\text { estado latente para } \\
\text { empreender em } \\
\text { indivíduos que não } \\
\text { possuem negócios, } \\
\text { mas apresentam } \\
\text { predisposição para } \\
\text { criá-los }\end{array}$ \\
\hline V & $\begin{array}{l}\text { Iizuka \& } \\
\text { Moraes } \\
(2014)\end{array}$ & $\begin{array}{l}\text { Construto } \\
\text { multidimensional } \\
\text { composto pelos fatores } \\
\text { auto eficaz, assume } \\
\text { riscos calculados, } \\
\text { planejador, detecta } \\
\text { oportunidades, } \\
\text { persistente, sociável, } \\
\text { inovador e líder } \\
\text { Construto } \\
\text { multidimensional } \\
\text { composto pelos fatores } \\
\text { auto eficaz, assume } \\
\text { riscos calculados, } \\
\text { planejador, detecta } \\
\text { oportunidades, }\end{array}$ & $\begin{array}{l}\text { Schmidt e Bohnenberger } \\
\text { (2009): proposição de } \\
\text { dimensões para o } \\
\text { construto a partir de } \\
\text { levantamento } \\
\text { assistemático da } \\
\text { literatura, não } \\
\text { confirmadas quando } \\
\text { submetidas à análise } \\
\text { empírica pelos próprios } \\
\text { autores } \\
\text { Brants et al. (2015): } \\
\text { concepção para o } \\
\text { construto inspirada no } \\
\text { modelo de traços por } \\
\text { meio de fatores }\end{array}$ & $\begin{array}{l}\text { Inadequação do } \\
\text { modelo de traços e, } \\
\text { consequentemente, } \\
\text { da nomenclatura } \\
\text { perfil para } \\
\text { compreender as } \\
\text { características } \\
\text { pessoais dos } \\
\text { empreendedores } \\
\text { (Frese \& Gielnik, } \\
\text { 2014). A miscelânea } \\
\text { de dimensões sem } \\
\text { confirmação empírica } \\
\text { indica fragilidade } \\
\text { para o construto, o } \\
\text { qual também }\end{array}$ \\
\hline
\end{tabular}


persistente, sociável, inovador e líder

propostos por McClelland apresenta sobreposição conceitual frente aos demais conceitos que versam sobre as características pessoais dos empreendedores
Brants et al. Construto

(2015) multidimensional coomposto pelos fatores busca de oportunidade e iniciativa, persistência, comprometimento, exigência de qualidade e eficiência, correr riscos calculados, estabelecimento de metas, busca de informações, planejamento e monitoramento sistemático, persuasão e rede de contatos, independência e autoconfiança

\begin{tabular}{|c|c|c|c|c|}
\hline VI & $\begin{array}{l}\text { Shane \& } \\
\text { Nicolaou } \\
(2013) \\
\text { Choe et al. } \\
(2013)\end{array}$ & $\begin{array}{l}\text { Quantidade de dólares } \\
\text { obtidos mensalmente } \\
\text { pelo empreendedor por } \\
\text { meio do próprio negócio } \\
\text { Autoavaliação do } \\
\text { empreendedor quanto } \\
\text { ao resultado do próprio } \\
\text { negócio frente às } \\
\text { demais empresas do } \\
\text { mesmo nicho de } \\
\text { mercado }\end{array}$ & $\begin{array}{l}\text { Modelos concebidos a } \\
\text { partir de ideias } \\
\text { propostas pelos autores, } \\
\text { não dispondo de aporte } \\
\text { anterior para as } \\
\text { elaborações }\end{array}$ & $\begin{array}{l}\text { Adequação do } \\
\text { construto para } \\
\text { mensurar a } \\
\text { performance } \\
\text { organizacional ao } \\
\text { enfatizar a dimensão } \\
\text { financeira e analisar } \\
\text { o desempenho } \\
\text { empreendedor ao } \\
\text { focar na perspectiva } \\
\text { de autorrelato. O } \\
\text { construto adquire } \\
\text { maior robustez para } \\
\text { compreender } \\
\text { características } \\
\text { pessoais ao ser } \\
\text { empregado em } \\
\text { análises multiniveis } \\
\text { que visem relacionar } \\
\text { o resultado financeiro } \\
\text { com o autorrelato do } \\
\text { empreendedor. }\end{array}$ \\
\hline
\end{tabular}

Nota. I. Competências Empreendedoras; II. Atitude Empreendedora; III. Personalidade Empreendedora; IV. Potencial Empreendedor; V. Perfil Empreendedor; VI. Performance Empreendedora

\section{DISCUSSÃO}

Baseando-se na análise teórico-conceitual realizada verifica-se que existem inconsistências conceituais na literatura acerca das características pessoais dos empreendedores, uma vez que se nota entre os diversos construtos elevada dispersão teórica e sobreposição conceitual. Apreendem-se também problemas na operacionalização dos fatores referentes aos construtos, pois entre 
construtos com nomenclatura similar a estrutura fatorial não é compatível ou não possui significado equivalente. Outro problema da literatura da área refere-se à excessiva proposição de termos sem a devida definição constitutiva ou marco teórico que demonstre a validade daquela proposição. Entre os construtos analisados, a atitude empreendedora mostrou-se como aquele com definição constitutiva e operacional de maior clareza na literatura revisada. Ademais, também se verifica relevância nos conceitos de competência empreendedora, personalidade empreendedora, potencial empreendedor e performance empreendedora desde que sejam respeitados os aspectos teóricos que diferenciam suas proposições.

No caso das competências empreendedoras deve-se enfatizar os comportamentos e habilidades de forma contextualizada com ênfase na geração de resultados, tal como na acepção de Boyatzis (1982), a fim de distingui-la da atitude empreendedora. Por sua vez, o construto personalidade empreendedora deve ter em sua nomenclatura alguma referência ao modelo Big Five, pois não se trata de um construto inédito, mas de um agrupamento específico de fatores previamente existente na concepção teórica dos Cinco Grandes fatores de personalidade (John \& Srivastava, 1999).

Já o construto potencial empreendedor também é passível de distinção entre os demais conceitos desde que compreendido de forma semelhante a proposta de Iizuka e Moraes (2014), a qual versa sobre aspectos pessoais que predispõem ao empreendedorismo latente entre aqueles que ainda não possuem um negócio, mas vivenciam experiências que podem favorecer a expressão do empreendedorismo no futuro. De outra forma, ao tratar exclusivamente sobre aspectos pessoais, o construto potencial empreendedor parece diluir-se em meio aos conceitos de atitude e competências empreendedoras, perdendo o aspecto que marca sua relevância na literatura. O construto performance empreendedora também é distinguível dos demais ao dirigir para domínios voltados ao desempenho, sendo relevante tanto para avaliação no nível organizacional quanto no nível individual. Para aferir as características pessoais, a operacionalização do construto no nível individual em forma de autorrelato com a nomenclatura desempenho em vez de performance mostra-se mais adequada.

Em relação ao construto perfil empreendedor, é importante ressaltar que a termologia perfil designa erroneamente o objeto ao qual o construto se refere, uma vez que as características pessoais investigadas por meio do construto apresentam maior compatibilidade com a noção de atitudes no contexto do empreendedorismo (Frese \& Gielnik, 2014). Os traços propostos na literatura por McClelland (1972) no início da investigação das características pessoais dos empreendedores serviram apenas como elementos fundantes para a proposição de medidas atitudinais voltadas às características pessoais dos empreendedores, sendo, portanto, desaconselhável nomear o construto como perfil ou operacionalizá-lo a partir da noção de traços estáveis por se tratar 
essencialmente de atitudes do indivíduo frente às características individuais relacionadas com a expressão do empreendedorismo.

Dessa forma, apesar da recorrente utilização do termo perfil empreendedor em senso comum e em alguns estudos da literatura para designar as características pessoais dos empreendedores, não é possível verificar aporte teórico que justifique a relevância e reprodução do termo em investigações posteriores a partir da análise teórico-conceitual empreendida. Como alternativa ao perfil empreendedor (Schmidt \& Bohnenberger, 2009), sugere-se a utilização do construto atitude empreendedora em investigações futuras que busquem aferir características pessoais associadas ao empreendedorismo (Robinson et al., 1991). Além dos aspectos descritos, apresentam-se como evidências favoráveis ao uso do construto atitude empreendedora a adequação do modelo tripartite de atitudes para compreender as características pessoais dos empreendedores (Choe et al., 2013; Lope-Pihie \& Bagheri, 2011) e a consistência teórica do modelo tripartite de atitudes dentro da ciência psicológica, especificamente em medidas voltadas para temas que fazem interface com o contexto das organizações e do trabalho (Lindzey et al., 1998; Siqueira, 2002).

\section{CONSIDERAÇÕES FINAIS}

O presente estudo identificou na literatura os construtos utilizados para designar as características pessoais dos empreendedores, bem como realizou uma análise teórico-conceitual daqueles recorrentes, a fim de propiciar maior clareza nas elaborações sobre o tema. A principal contribuição do estudo referese à sistematização e distinção entre os conceitos ligados às características pessoais dos empreendedores, de forma a possibilitar que as elaborações futuras se refiram ao fenômeno com maior apropriação teórica. Destaca-se como principal limitação da investigação a natureza exploratória e descritiva da análise teórico-conceitual empreendida, a qual pode ter seu valor acrescido quando associada às contribuições futuras propiciadas por metanálises e evidências empíricas geradas por investigações ulteriores.

Ademais, faz-se mister ressaltar que estudos futuros devem manter continuamente a sistematização do corpo de conhecimento relacionado às características dos empreendedores, visando maior clareza conceitual e operacional dos construtos, a fim de contribuir numa agenda nacional que vise 0 desenvolvimento de medidas e indicadores sobre o tema. Por último, é importante destacar que se por um lado as dificuldades teórico-conceituais apresentadas aparentam obstaculizar o desenvolvimento linear de compreensões sobre o fenômeno. Por outro, somente elas possibilitam rupturas e saltos qualitativos na produção do conhecimento sobre as características pessoais dos empreendedores, a partir da compreensão plural que somente os olhares interdisciplinares são capazes de impactar na produção do conhecimento. 


\section{DECLARAÇÃO DE CONFLITOS DE INTERESSE}

Não há conflitos de interesse.

\section{REFERÊNCIAS}

Os artigos marcados com o símbolo * foram utilizados na análise dos dados da revisão da literatura.

*Arribas, I., Hernandez, P., Urbano, A., \& Vila, J. (2012). Are social and entrepreneurial attitudes compatible? A behavioral and self-perceptional analysis. Management Decision, 50(1), 1739-1757. doi: $10.1108 / 00251741211279576$

Bastos, A. V. B. (1994). Confusão conceitual no estudo de atitudes no trabalho. Temas em Psicologia, 2(3), 97-108. Recuperado em http://pepsic.bvsalud.org/pdf/tp/v2n3/v2n3a10.pdf

Boyatzis, R. E. (1982). The competent manager: A model for effective performance. New Jersey, NY: John Wiley \& Sons.

*Brants, J., Oliveira, C., Casemiro, Í., Licório, A., \& Reboli, R. (2015). Empreendedorismo acadêmico no curso de administração da UNIR. Revista Pretexto, 16(2), 59-74. doi:10.21714/pretexto.v16i2.2368

Braudel, F. (1982). Civilization and Capitalism, 15th-18th Century: The wheels of commerce (Vol. 2). Oakland, CA: University of California Press.

*Choe, K. L., Loo, S. C., \& Lau, T. C. (2013). Exploratory study on the relationship between entrepreneurial attitude and firm's performance. Asian Social Science, 9(4), 144-149. doi:10.5539/ass.v9n4p144

Coelho-Junior, F. A. C., \& Borges-Andrade, J. E. (2011). Efeitos de variáveis individuais e contextuais sobre desempenho individual no trabalho. Estudos de Psicologia, 16(2), 111-120. doi:10.1590/S1413-294X2011000200001

Cooley, L. (1990). Entrepreneurship training and the strengthening of entrepreneurial performance. Washington: USAID.

Dana, L. P. (2007). Handbook of research on ethnic minority entrepreneurship: $A$ coevolutionary view on resource management. Northampton, MA: Edward Elgar Publishing.

Frese, M., \& Gielnik, M. M. (2014). The psychology of entrepreneurship. Annual Review of Organizational Psychology and Organizational Behavior, 1(1), 413-438. doi:10.1146/annurev-orgpsych-031413-091326

Fontanella, B. J. B., Luchesi, B. M., Saidel, M. G. B., Ricas, J., Turato, E. R., \& Melo, D. G. (2011). Amostragem em pesquisas qualitativas: Proposta de procedimentos para constatar saturação teórica. Cadernos de Saúde Pública, 27(2), 388-394. doi:10.1590/S0102-311X2011000200020 
*Garzón, M. D. (2010). A comparison of personal entrepreneurial competences between entrepreneurs and CEOs in service sector. Service Business, 4(3), 289-303. doi: $10.1007 /$ s11628-009-0090-6

Hébert, R. F., \& Link, A. (2010). Historical perspectives on the entrepreneur. Foundations and Trends in Entrepreneurship, 2(4), 261-408. doi: $10.1561 / 0300000008$

Hisrich, R., Langan-Fox, J., \& Grant, S. (2007). Entrepreneurship Research and Practice: a call to action for psychology. American Psychologist, 62(6), 575589. doi: $10.1037 / 0003-066 X .62 .6 .575$

Hoselitz, B. F. (1952). Entrepreneurship and Economic Growth. American Journal of Economics and Sociology, 12(1), 97-111. doi:10.1111/j.15367150.1952.tb00480.x

Hoselitz, B. F. (1957). Noneconomic factors in economic development. The American Economic Review, 47(2), 28-41.

*Iizuka, E. S., \& Moraes, G. H. S. M. (2014). Análise do potencial e perfil empreendedor do estudante de administração e o ambiente universitário: Reflexões para instituições de ensino. Administração: Ensino e Pesquisa, 15(3), 593-630. doi:10.13058/raep.2014.v15n3.16

John, O. P., \& Srivastava, S. (1999). The big five trait taxonomy: History, measurement, and theoretical perspectives. In O. P., John, R. W., Robins, \& L. A. Pervin, (Eds.). Handbook of personality: Theory and research (p. 102138). New York, NY: Guilford Press.

Lindzey, G., Gilbert, D., \& Fiske, S. T. (1998). The handbook of social psychology. London, UK: Oxford University Press.

*Lope-Pihie, Z. A., \& Bagheri, A. (2011). Malay secondary school students' entrepreneurial attitude orientation and entrepreneurial self-efficacy: A descriptive study. Journal of Applied Sciences, 11(2), 316-322. doi: $10.3923 /$ jas.2011.316.322

Man, T. W., \& Lau, T. (2000). Entrepreneurial competencies of SME owner/managers in the Hong Kong services sector: A qualitative analysis. Journal of Enterprising Culture, 8(3), 235-254. doi: $10.1142 / S 0218495800000139$

*Mathieu, C., \& St-Jean, É. (2013). Entrepreneurial personality: The role of narcissism. Personality and Individual Differences, 55(5), 527-531. doi: $10.1016 /$ j.paid.2013.04.026

Matthews, C. H., \& Moser, S. B. (1996). A Longitudinal Investigation of the Impact of Family Background. Journal of Small Business Management, $34(2), 29-43$.

McClelland, D. C. (1965). Achievement-Motivation can be developed. Harvard Business Review, 43(6), 6-25. doi:10.1225/65609

McClelland, D. C. (1972). A Sociedade Competitiva Realização e Progresso Social. Rio de Janeiro, RJ: Expressão e Cultura. 
McCline, R. L., Bhat, S., \& Baj, P. (2000). Opportunity recognition: An exploratory investigation of a component of the entrepreneurial process in the context of the health care industry. Entrepreneurship Theory and Practice, 25(2), 81-94. https://doi.org/10.1177\%2F104225870002500205

*Morales, C., \& Feldman, P. M. (2013). Entrepreneurial skills, significant differences between Serbian and German entrepreneurs. Journal of CENTRUM Cathedra, 6(1), 1-27. Recuperado de https://ssrn.com/abstract $=2236459$

Murray, E. J., \& Cabral, Á. (1978). Motivação e Emoção. Rio de Janeiro, RJ: Zahar.

*Obschonka, M., Schmitt-Rodermund, E., Silbereisen, R. K., Gosling, S. D., \& Potter, J. (2013). The regional distribution and correlates of an entrepreneurship-prone personality profile in the United States, Germany, and the United Kingdom: A socioecological perspective. Journal of Personality and Social Psychology, 105(1), 104-122. doi: $10.1037 / \mathrm{a} 0032275$

*Obschonka, M., Silbereisen, R. K., \& Schmitt-Rodermund, E. (2012). Explaining entrepreneurial behavior: Dispositional personality traits, growth of personal entrepreneurial resources, and business idea generation. Career Development Quarterly, 60(2), 178-190. doi:10.1002/j.21610045.2012.00015.x

O'Reilly, M., \& Parker, N. (2013). 'Unsatisfactory Saturation': a critical exploration of the notion of saturated sample sizes in qualitative research. Qualitative Research, 13(2), 190-197. doi:10.1177/1468794112446106

Polit, D. F., \& Beck, C. T. (2006). The content validity index: Are you sure you know what's being reported? Critique and recommendations. Research in Nursing \& Health, 29(5), 489-497. doi:10.1002/nur.20147

*Rezaei-Zadeh, M., Hogan, M., O'Reilly, J., Cleary, B., \& Murphy, E. (2014). Using interactive management to identify, rank and model entrepreneurial competencies as universities' entrepreneurship curricula. The Journal of Entrepreneurship, 23(1), 57-94. doi:10.1177/0971355713513353

Robinson, P., B., Stimpson, D., V., Huefner, J., \& Hunt, H., K. (1991). An attitude approach to the prediction of entrepreneurship. Entrepreneurship: Theory and Practice, 15(4),

$13-31$.

https://doi.org/10.1177\%2F104225879101500405

*Santandreu-Mascarell, C., Garzon, D., \& Knorr, H. (2013). Entrepreneurial and innovative competences, are they the same? Management Decision, 51(5), 1084-1095. doi:10.1108/MD-11-2012-0792

*Santos, S. C., Caetano, A., Curral, L., \& Spagnoli, P. (2010). How to assess entrepreneurial potential. Washigton, DC: International Council for Small Business. Recuperado de https://goo.gl/BWZCpk 
Scherer, R. F., Adams, J. S., \& Wiebe, F. A. (1989). Developing entrepreneurial behaviours: A social learning theory perspective. Journal of Organizational Change Management, 2(3), 16-27. doi:10.1108/EUM0000000001186

Schmidt, S., \& Bohnenberger, M. C. (2009). Perfil Empreendedor e Desempenho Organizacional. Revista de Administração Contemporânea, 13(3), 450-467. http://dx.doi.org/10.1590/S1415-65552009000300007

Schmitt-Rodermund, E. (2004). Pathways to successful entrepreneurship: Parenting, personality, early entrepreneurial competence, and interests. Journal of Vocational Behavior, 65(3), 498-518. doi: $10.1016 / j . j v b .2003 .10 .007$

Schmitt-Rodermund, E. (2007). The long way to entrepreneurship: Personality, parenting, early interests, and competencies as precursors for entrepreneurial activity among the "Termites". In R. K., Silbereisen, \& R. M. Lerner (Eds.), Approaches to Positive Youth Development (pp. 205-224). London, UK: Sage Publication.

Schröder, E., \& Schmitt-Rodermund, E. (2006). Crystallizing enterprising interests among adolescents through a career development program: The role of personality and family background. Journal of Vocational Behavior, 69(3), 494-509. doi:10.1016/j.jvb.2006.05.004

Schumpeter, J. A. (1939). Business Cycles (Vol. 1). London, UK: Cambridge University Press.

Schumpeter, J. (1985). Teoria do desenvolvimento econômico: Uma investigação sobre lucros, capital, crédito, juro e o ciclo econômico. São Paulo, SP: Abril Cultural.

*Shane, S., \& Nicolaou, N. (2013). The genetics of entrepreneurial performance. International Small Business Journal, 31(5), 473-495. doi: $10.1177 / 0266242613485767$

Siqueira, M. M. M. (2002). Medidas do comportamento organizacional. Estudos de Psicologia, 7(S), 11-18. http://dx.doi.org/10.1590/S1413294X2002000300003

*Souza, J. R. M. D., \& Silva, C. E. (2011). Metodologias de estímulo a criatividade e inovação no desenvolvimento de empreendedores: Uma revisão teórica. Revista Brasileira de Administração Científica, 2(1), 68-86. doi: 10.6008\%2FESS2179-684X.2011.001.0004

Tamayo, N., \& Abbad, G. D. S. (2006). Autoconceito profissional e suporte à transferência e impacto do treinamento no trabalho. Revista de Administração Contemporânea, 10(3), 9-28. doi:10.1590/S141565552006000300002

Trotter, R. T. (2012). Qualitative research sample design and sample size: Resolving and unresolved issues and inferential imperatives. Preventive Medicine, 55(5), 398-400. doi:10.1016/j.ypmed.2012.07.003 
Vale, G. M. V. (2014). Empreendedor: Origens, concepções teóricas, dispersão e integração. RAC Revista de Administração Contemporânea, 18(6), 874-891. Recuperado de http://www.redalyc.org/html/840/84032519009/

Vérin, H. (1982). Entrepreneurs, entreprise: histoire d'une idée (Vol. 2). Paris, IDF: Presses Universitaires de France.

Weber, M. (1958). A Ética Protestante e o Espírito do Capitalismo. São Paulo, SP: Pioneira.

*Zampier, M. A., \& Takahashi, A. R. (2011). Competências empreendedoras e processos de aprendizagem empreendedora: Modelo conceitual de pesquisa. Cadernos EBAPE.BR, 9(1), 564-585. doi:10.1590/S167939512011000600007

Sobre os autores

Pedro Afonso Cortez é Doutorando em Psicologia pela Universidade São Francisco, Mestre e Graduado em Psicologia pela Universidade Federal de Uberlândia. Recebeu financiamento de pesquisa para a presente investigação na modalidade bolsa (mestrado) pela CAPES (Coordenação de Aperfeiçoamento de Pessoal de Nível Superior). cor.afonso@gmail.com Heila Magali da Silva Veiga é Docente do Instituto de Psicologia da Universidade Federal de Uberlândia, Graduada em Psicologia, Mestre e Doutora em Psicologia Social, das Organizações e do Trabalho pela Universidade de Brasília. heila.veiga@gmail.com

Certificamos que todos os autores participaram suficientemente do trabalho para tornar pública sua responsabilidade pelo conteúdo. A contribuição de cada autor pode ser atribuída como se segue: Pedro Afonso Cortez e Heila Magali da Silva Veiga contribuíram para a conceitualização e execução da investigação, preparação do artigo e revisão final do manuscrito.

Os autores agradecem a CAPES (Coordenação de Aperfeiçoamento e Pessoal de Nível Superior) pelo financiamento prestado na modalidade bolsa (mestrado) para o primeiro autor do manuscrito. Agradecem, ademais, a infraestrutura oferecida pelos integrantes do Laboratório de Pesquisa em Psicologia Social e do Trabalho do Instituto de Psicologia da Universidade Federal de Uberlândia para a realização da investigação.

Recebido em: 03/01/2017

Revisado em: 12/07/2017

Aceito em: $14 / 07 / 2017$ 